"This is the peer reviewed version of the following article: [Chem. Eur. J. 2017, 23 (22), 5338], which has been published in final form at [DOI 10.1039/c0dt00166j]. This article may be used for noncommercial purposes in accordance with Wiley Terms and Conditions for Self-Archiving."

\title{
Electronic Structure Studies on the Whole Keplerate Family: Predicting New Members
}

Dolores Melgar, ${ }^{\mathrm{a}}$ Nuno A. G. Bandeira, ${ }^{\mathrm{a}}$ Carles $\mathrm{Bo}^{\mathrm{a}, \mathrm{b},{ }^{*}}$

a. Institute of Chemical Research of Catalonia (ICIQ), The Barcelona Institute of Science and Technology, Av. dels Països Catalans, 16, 43007 Tarragona, Spain.

b. Departament de Química Física i Inorgànica, Universitat Rovira i Virgili, Av. dels Països Catalans, 26, 43007

Tarragona, Spain.

\begin{abstract}
The present paper presents a comprehensive study of the electronic structure of nano-scale molecular oxide capsules of the type $\left[\left\{M^{V /}\left(M^{V / 1}\right)_{5} O_{21}\right\}_{12}\left\{M^{\prime V}{ }_{2} O_{2}(\mu-X)(\mu-Y)\left(L^{n-}\right)\right\}_{30}\right]^{(12+n)-}$, where $M, M^{\prime}=M o$, $W$, and the bridging ligands $X, Y=O, S$, carried out by means of density functional theory. Discussion of the electronic structure of these derivatives is focused on the thermodynamic stability of each of the structures, the one having the highest gap being $M=W, M^{\prime}=M o, X=Y=S$. For the most well known structure $M=M^{\prime}=M o, X=Y=O,\left[M_{132} O_{372}\right]^{12-}$, the chemical of several ligands to the $\left\{M^{V}{ }_{2} O_{2}(\mu-O)_{2}\right\}$ linker moiety produces negligible effects on its stability which is evidence of a strong ionic component in these bonds. The existence of hitherto unknown species, namely $W_{132}$ with both bridging alternatives is discussed and put into context with our findings.
\end{abstract}

\section{Introduction}

In the last years, new molecular nano-clusters have emerged in the context of polyoxometalate (POM) science. ${ }^{[1]}$ A good example of these nano-systems is the so-called Keplerates family. The term Keplerate stands for a family of POMs with nanometric size and an internal cavity that makes these nano-capsules an excellent environment to study the effect of confinement on the encapsulated species. ${ }^{[2]}$ Keplerates can be considered thus as spherical nano-containers, the vast majority of them holding 102 or 132 metal atoms (Figure 1), ${ }^{[2-3]}$ although recently an icosidodecahedral structure was identified containing just 42 titanium atoms. ${ }^{[4]}$ The difference between the 102 or the 132 atoms systems lays on the building blocks that form the Keplerate structure. The most characteristic building block that can be found over all the Keplerate family is the pentagonal unit. From Euler's theorem, 12 of these pentagonal motifs are needed in order to build a spherical structure. These 12 pentagonal pieces are joined together by 30 linker units. The size of these linkers (that can be either 
monomers or dimers) constitutes the main difference between the $M_{132}$ and $M_{102}$ Keplerates. This paper aims at studying the electronic properties of Keplerate systems with dimeric linkers, with general formula $\left[\left\{M^{V 1}\left(M^{V 1}\right)_{5} O_{21}\right\}_{12}\left\{M^{\prime V}{ }_{2} O_{2}(\mu-X)(\mu-Y)\left(L^{n-}\right)\right\}_{30}\right]^{(12+n)}$, where $M$ and $M^{\prime}$ are the metal positions that can be Mo or $\mathrm{W}$ atoms). $\mathrm{X}$ and $\mathrm{Y}$ stand for the bridging sites in the linkers and can be both $\mathrm{O}$ or $\mathrm{S}$ atoms. Using a simplified notation, we will address to Keplerate systems as $\mathrm{M}_{72} \mathrm{M}_{60}^{\prime}(\mu-$ $X)(\mu-Y)$, depending on the particular composition of each system. In some cases, when the linkers present only oxo-bridges the description of such positions is omitted.

In the general formula of Keplerates, $L$ represents a bidentate ligand that can be coordinated to the inner surface of the capsule. These ligands are usually bidentate oxygen donor anions, as formate, ${ }^{[5]}$ acetate ${ }^{[2 b]}$ monochloroacetate,${ }^{[5 c]}$ sulfate, ${ }^{[2 b, 6]}$ sulfite ${ }^{[7]}$ hypophosphite, ${ }^{[8]}$ hydrogen phosphate ${ }^{[9]}$, selenate ${ }^{[10]}$ valerate, ${ }^{[11]}$, carbonate ${ }^{[8]}$ carboxylates in general, ${ }^{[12]}$ or even dicarboxylates. ${ }^{[13]}$ These ligands are labilely bonded to the inner surface of the capsule. Therefore, they are able to exchange their positions inside of the Keplerate or even with solvated anions from the outer medium through the pores. ${ }^{[14]}$ The particularities of the coordinated anions alter the capsule's properties, as the charge, the hydrophobic character of the inner surface, and the size of the internal cavity. Therefore, the exchange of ligands allows the tuneability of the Keplerate capsules for different purposes.
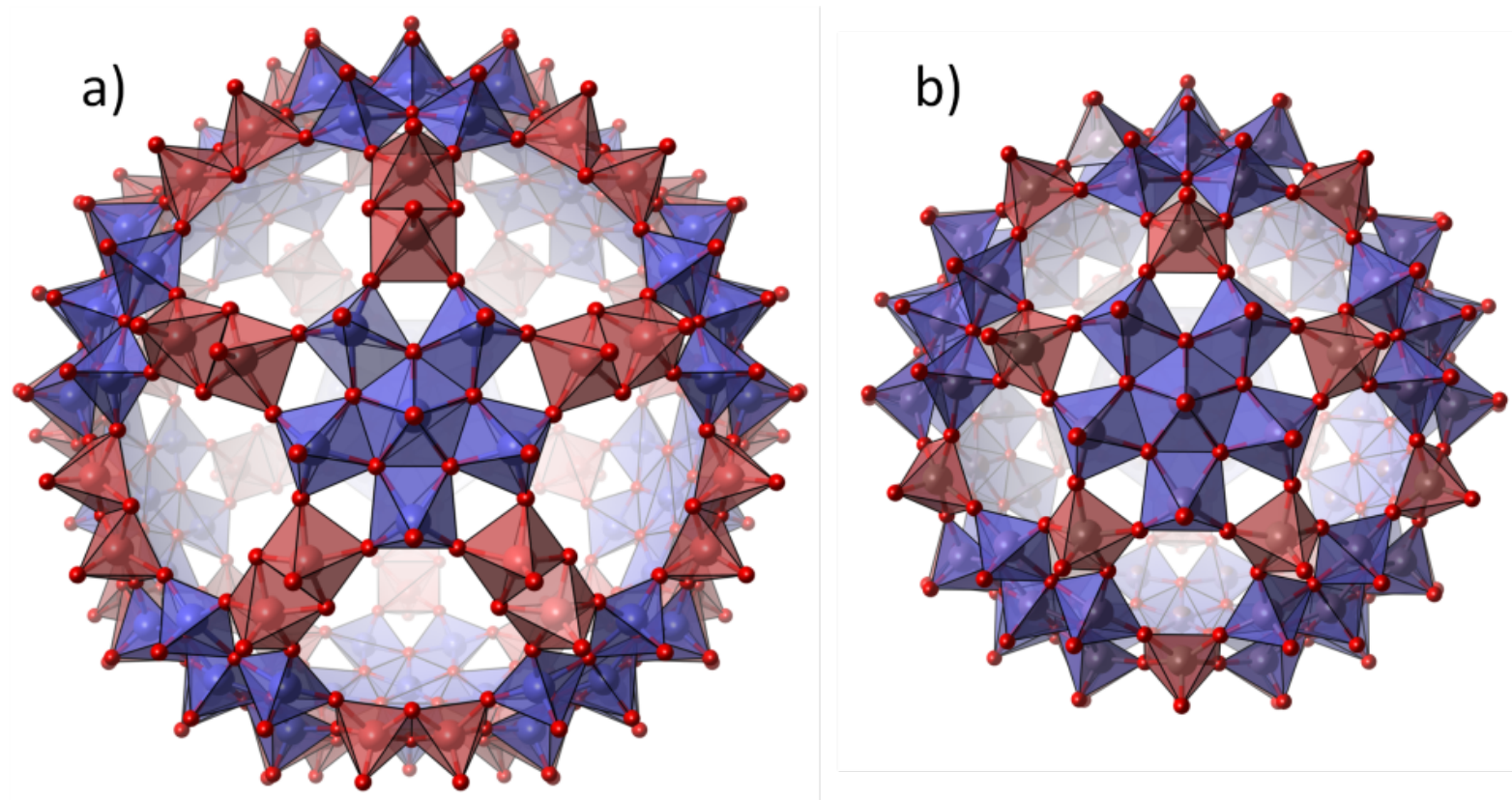

Figure 1: Polyhedral representation of two typical Keplerate structures: $M_{132}$ (a) and $M_{102}$ (b). Pentagonal motifs are represented in blue and equivalent for both systems. In contrast, linker units (red polyhedra) are monomeric in the case of $\mathrm{M}_{102}$ and dimeric for $\mathrm{M}_{132}$ systems.

Historically, the first Keplerate is the $\mathrm{Mo}_{132}(\mu-O)_{2}$ and it was synthesized in 1998 by Müller and collaborators. ${ }^{[15]}$ After this amazing discovery, Müller's group realized that the composition of building blocks could be altered, giving rise to several interesting structures. For instance, instead of the original $\mathrm{Mo}_{2}{ }_{2} \mathrm{O}_{2}(\mu-\mathrm{O})_{2}$, different linker units were used introducing new metal ions as $\mathrm{Fe}^{\mathrm{III}}$ in $\mathrm{Mo}_{72} \mathrm{Fe}_{30},{ }^{[16]}$ monomeric $\mathrm{Mo}^{\mathrm{V}}$ in $\mathrm{Mo}_{102},{ }^{[16]} \mathrm{V}^{\mathrm{IV}}$ in $\mathrm{Mo}_{72} \mathrm{~V}_{30},{ }^{[17]}$ and $\mathrm{Cr}^{\mathrm{III}}$ in $\mathrm{Mo}_{72} \mathrm{Cr}_{30}{ }^{\left[{ }^{[18]}\right.}$ The composition of the pentagonal building blocks can also be altered changing the Mo metal centers by $\mathrm{W}$ atoms. Examples of these $\mathrm{W}$-based pentagons can be found in $\mathrm{W}_{72} \mathrm{Mo}_{60}{ }^{[19]}$ and in $\mathrm{W}_{72} \mathrm{Fe}_{30}{ }^{\left[{ }^{[19]}\right.}$ Moreover, in 
some cases the characteristic icosahedral symmetry of these systems can be somehow distorted, as in the $\mathrm{Mo}_{75} \mathrm{~V}_{20}$ capsule. ${ }^{[20]}$ The latest modification introduced in Keplerates composition was regarding the bridging positions in the linker units. Sulfur atoms, as in $\mathrm{Mo}_{132}(\mu-\mathrm{S})_{2}{ }^{[21]}$ and $\mathrm{W}_{72} \mathrm{Mo}_{60}(\mu-$ $\mathrm{S}_{2}{ }^{[22]}$ can substitute the traditional oxo-bridges. Furthermore, a mixed-bridges possibility has also been reported as in $\mathrm{W}_{72} \mathrm{Mo}_{60}(\mu-\mathrm{O})(\mu-S){ }^{[23]}$

Although the Keplerate family is short and young, it is revealing promising properties. $\mathrm{Mo}_{72} \mathrm{Fe}_{30}$ was reported as an active catalyst for the selective oxidation of sulfides, ${ }^{[24]}$ and also used to form hybrid films for building electro-catalytic electrodes. ${ }^{[25]}$ Of most interest are those cases reporting catalysis occurring inside the Keplerate. In the first example of such a kind of nano-reactor the authors demonstrated, both experimentally and computationally, the mechanism of the hydrolysis of methyl tert-butyl ether inside the $\mathrm{Mo}_{132}$ capsule. ${ }^{[26]}$ Also, it has been proved that the $\mathrm{Mo}_{132}$ Keplerate is able to modify the regioselectivity of the Huisgen reaction. ${ }^{[27]}$ Other examples refer to the uptake and oxidation of simple gases such $\mathrm{CO}_{2}{ }^{[8,28]}$ and $\mathrm{SO}_{2},{ }^{[7]}$ inside the $\mathrm{Mo}_{132}$ capsule: in both cases the products were characterized by X-Ray. Several other catalytic oxidation processes have been reported, which in our opinion probably occur outside the capsule. ${ }^{[29]}$ Besides their catalytic applications, new materials a being prepared employing Keplerates. For instance, they have been combined with surfactants, ${ }^{[30]}$ ionic liquids, ${ }^{[31]}$ ionic crystals, ${ }^{[32]}$ and gold nanoparticles. ${ }^{[33]}$ Last but not least, $\mathrm{Mo}_{132}$ showed activity for disrupting peptides aggregation related with Alzheimer's disease. ${ }^{[34]}$

This paper presents a DFT study on the whole Keplerate family, which includes those known species described above incremented with unsynthesized yet potential members, such as the full tungsten analogs $W_{132}, W_{132}(\mu-S)_{2}$ and $W_{132}(\mu-O)(\mu-S)$, and $M_{132}(\mu-O)(\mu-S)$. We aimed at complementing a preliminary study ${ }^{[35]}$ on $\mathrm{Mo}_{132}(\mu-\mathrm{O})_{2}$ and $\mathrm{W}_{72} \mathrm{Mo}_{60}(\mu-\mathrm{O})_{2}$ empty capsules, but also at analyzing the effect of the 30 ligands coordinated at the bridging metal atoms, and the effect of the 72 water molecules in the pentagonal motifs. Ligands include mono-anionic species hypophosphite, formate, acetate, acrylate, bisulfate and bicarbonate, as well as di-anionic carbonate, selenate, sulfate and sulfite.

Electronic structure studies on Keplerates are scarce. In addition to our preliminary report, ${ }^{[35]}$ Kuepper et al. ${ }^{[36]}$ characterized the electronic structure of the $\mathrm{Mo}_{72} \mathrm{Fe}_{30}$ and $\mathrm{W}_{72} \mathrm{Fe}_{30}$ systems using plane-wave DFT methods. On the other hand classical molecular dynamics allowed us to study the layered structures that encapsulated water molecules form inside $\mathrm{Mo}_{132},{ }^{[37]}$ and more recently, the influence of the hydrophobic character of the counter-cations on the interactions with the Keplerates in aqueous solution. ${ }^{[38]}$ Other groups have used Monte Carlo methods to shed some light on the assembly of Keplerates. ${ }^{[39]}$ In this context, we hope that the results derived in the present study will be useful for developing parameters for molecular simulations.

\section{Computational Details}

All results presented herein correspond to full geometry optimizations carried out by means of the Amsterdam Density Functional package ADF. ${ }^{[40]}$ The GGA BP86 functional ${ }^{[41]}$ was used together with a Slater triple- $\zeta$ plus polarization basis set in all atoms. Relativistic corrections were introduced by the scalar-relativistic zero-order regular approximation (ZORA). ${ }^{[40 a, 42]}$ Solvent effects were included by using the continuum model COSMO ${ }^{[43]}$ For constructing the solvent cavity, the atomic radii values 
chosen were those Van der Waals radii from Allinger ${ }^{[44]}$ divided by 1.2. The numerical integration parameter that controls the precision of numerical integrals was set to 4.5. Geometry optimization at the LDA VWN ${ }^{[45]}$ level with the same basis sets, with and without implicit solvent were also carried out. The reader is addressed to the Supporting Information for further details. A data set collection which includes input files, and selected results is available online ${ }^{[46]}$ in the ioChem-BD repository. ${ }^{[47]}$

\section{Results}

Keplerates are discrete molecules but containing a huge number of atoms and electrons. This makes their electronic structure closer to bands in solids than to discrete and well-separated energy levels as found in small molecules. Therefore, we chose the Density of States (DOS), which is a function that represents the number of electronic levels per energy unit, to plot and analyze the electronic structure of these thousands of electrons systems. The Total Density of States (TDOS) includes all the existing energy levels. In contrast, the Partial Density of States (PDOS) gives the contribution to the TDOS of a specific atom type.

We have chosen the $\mathrm{Mo}_{132}(\mu-\mathrm{O})_{2}$ molecule to illustrate the typical DOS profile of Keplerates. Figure 2 shows the DOS of $\mathrm{Mo}_{132}$, from $-30 \mathrm{eV}$ to $10 \mathrm{eV}$. The deepest band in Figure 2 corresponds to the $2 \mathrm{~s}$ orbitals from the oxygen atoms (Figure 3a). Figure 2 also shows the characteristic oxo-band of polyoxometalates. The oxo-band includes the $p$ orbitals of the different oxygen atom types present on $\mathrm{Mo}_{132}$ (Figure $3 \mathrm{~b}, \mathrm{c}, \mathrm{d}$, and e). The HOMO band comprises 30 doubly occupied orbitals, including mainly contributions of $60 \mathrm{Mo}^{\mathrm{V}}$ atoms in the 30 linkers. Those electrons form the metal-metal bonds between the metal centers in the linker units (Figure 3f). Finally, the LUMO band includes all the $d$ orbitals from the Mo atoms in the pentagonal units (Figure $3 \mathrm{~g}$ ).

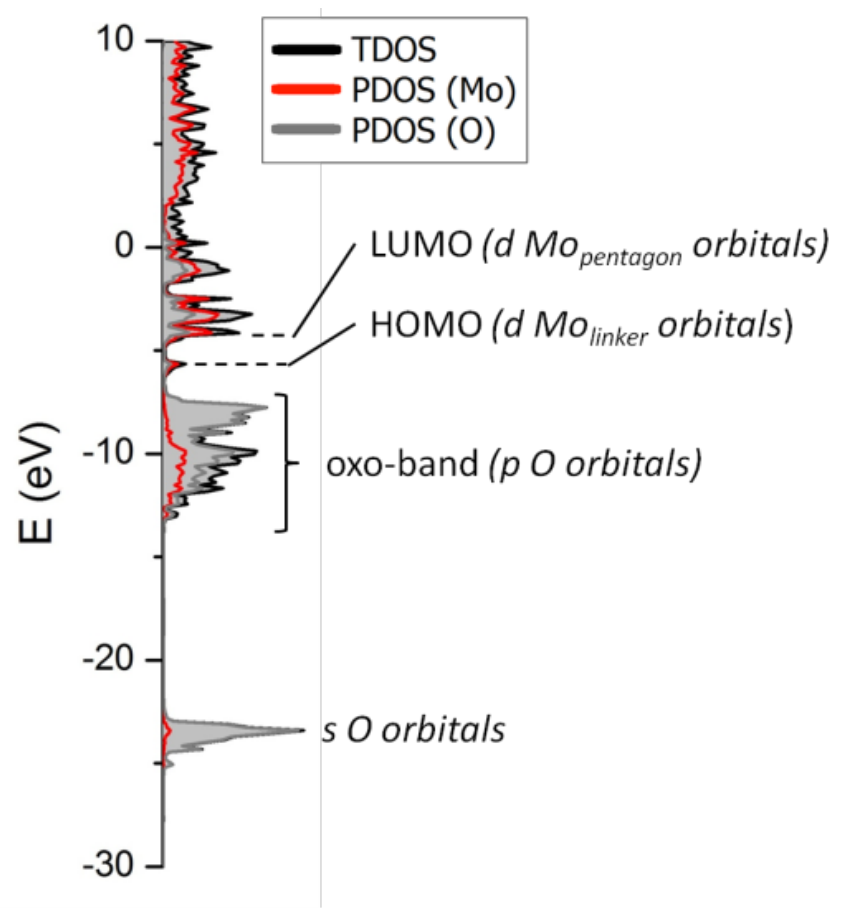


Figure 2: Plot of the DOS function for $\mathrm{Mo}_{132}$. The energy range comprises from $-30 \mathrm{eV}$ to $10 \mathrm{eV}$. Total Density of States (TDOS, black) and Partial Density of States (PDOS, red for Mo and grey for O).
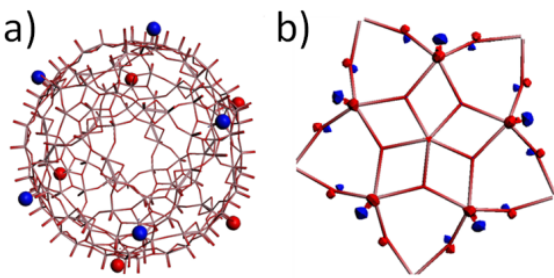
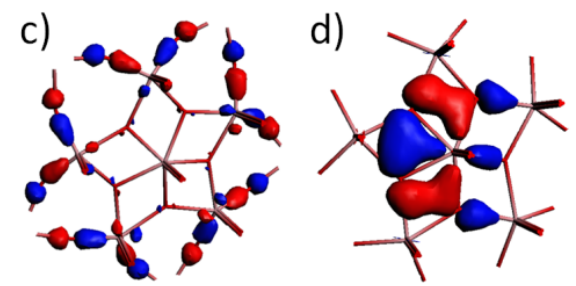

e)

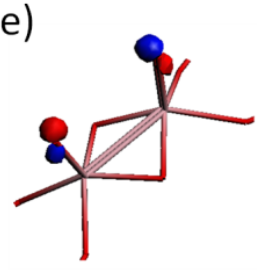

f)

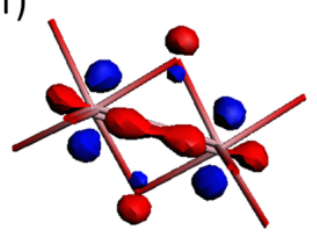

Figure 3: Examples of different types of Kohn-Sham orbitals for the $\mathrm{Mo}_{132}$ Keplerate. a) s oxygen orbitals, corresponding to the deepest band on Figure 2. b, c, d, e) p oxygen orbitals belonging to the oxo-band. f) HOMO band orbital, corresponding to the metal-metal bond, which involves the d orbitals of the linker Mo atoms. $g$ ) LUMO orbital related to the $d$ orbitals of the pentagonal Mo atoms. Note that for the LUMO orbital different colors were used to highlight the fact that this is a nonoccupied orbital.

While $\mathrm{Mo}_{132}(\mu-\mathrm{O})_{2}$ is the most well-known Keplerate, ${ }^{[15]} \mathrm{W}_{72} \mathrm{Mo}_{60}(\mu-\mathrm{O})(\mu-\mathrm{S})$ mixed-bridges is the latest discovered. ${ }^{[4]}$ The $X$-ray data of this compound presents crystallographic disorder in the bridging positions, while the metal-metal bond distance is the same for all the linkers. In other words: all the linkers hold one thio- and one oxo-bridge. This inherent disorder leads to different isomeric possibilities. Geometries of several isomers were thus studied and found that their relative energies fall within the $1 \mathrm{kcal} / \mathrm{mol}$ range. We thus conclude that the different isomers with mixed sulfur-oxo bridges are almost degenerate in terms of stability. The reader is addressed to the Supporting Information for further details on these isomeric possibilities. To compare the mixed bridge Keplerate with the other members of the family, we have chosen the most stable isomer as the reference structure.

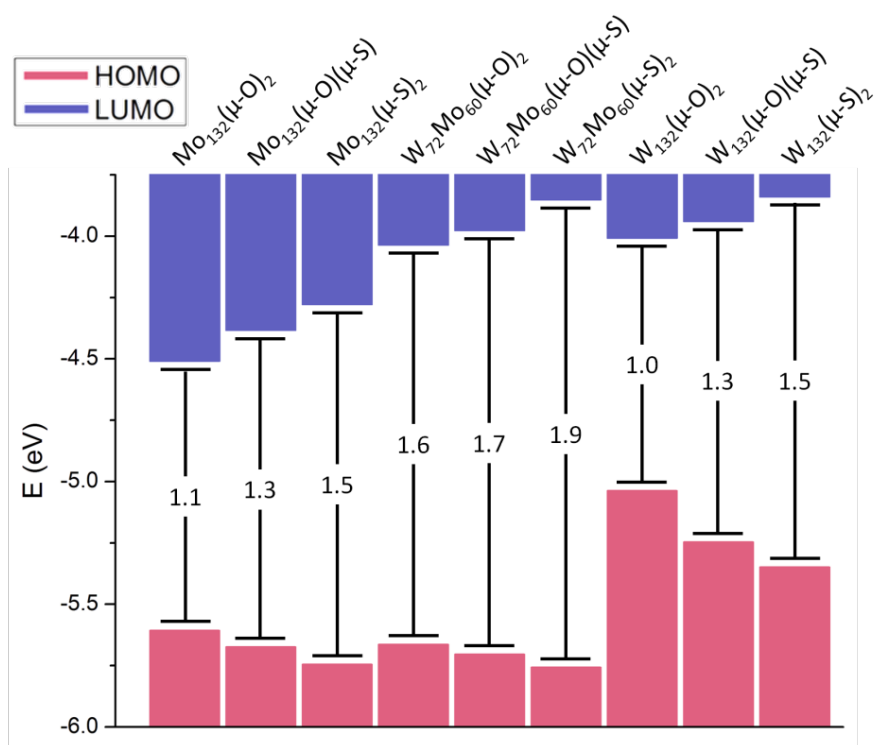


Figure 4: HOMO (pink) and LUMO (violet) energy levels (in eV) and its corresponding gap value for the whole Keplerate family.

Figure 4 shows how the ratio of W/Mo in the pentagonal units and $\mathrm{S}$ and/or $\mathrm{O}$ bridges in the linkers affect the HOMO-LUMO gap: the gap increases with the presence of $\mathrm{W}$ and $\mathrm{S}$. The HOMO-LUMO gap is an important measure of stability since it is directly related to quantities such as the chemical potential and chemical hardness. From the principle of maximum hardness as expounded by Pearson the most stable substances will have a higher gap.

The presence of $\mathrm{W}$ drives the LUMO level higher, because this level is related to the $5 \mathrm{~d}$ orbitals of the metal centers on the pentagon (Figure $3 \mathrm{~g}$ ). The existence of sulfur-bridges in the linkers makes the HOMO level decrease in energy, because the HOMO level is related to the metal-metal bonds in these units. When sulfur atoms populate the bridges, the distances between the two metal centers change from $2.64 \AA$ to $2.91 \AA$, making the Mo-Mo metal-metal bond weaker. As seen in Figure $3 f$ the bridging lobes are out of phase with the central Mo-Mo bonding region. Since the $3 p$ orbitals of sulfur are radially more external these will introduce more anti-bonding repulsion with the metal lobes resulting in an increased metal-metal bond distance to minimize this and also tighten the bridging angle. It is apparent that the energy of the HOMO level is a consequence of the influence of the bridging sites to the metal-metal bond. Summing up, regarding the HOMO-LUMO gap, $\mathrm{W}_{72} \mathrm{Mo}_{60}(\mu-\mathrm{S})_{2}$ is the most stable system among the experimentally synthesized Keplerates.
a) $\mathrm{Mo}_{132}(\mu-\mathrm{O})_{2}$
d) $\mathrm{W}_{72} \mathrm{Mo}_{60}(\mu-\mathrm{O})_{2}$
b) $\mathrm{Mo}_{132}(\mu-\mathrm{O})(\mu-\mathrm{S})$
e) $\mathrm{W}_{72} \mathrm{Mo}_{60}(\mu-\mathrm{O})(\mu-\mathrm{S})$
c) $\mathrm{Mo}_{132}(\mu-S)_{2}$
f) $\mathrm{W}_{72} \mathrm{Mo}_{60}(\mu-\mathrm{S})_{2}$
g) $\mathrm{W}_{132}(\mu-\mathrm{O})_{2}$
h) $W_{132}(\mu-O)(\mu-S)$
i) $W_{132}(\mu-S)_{2}$
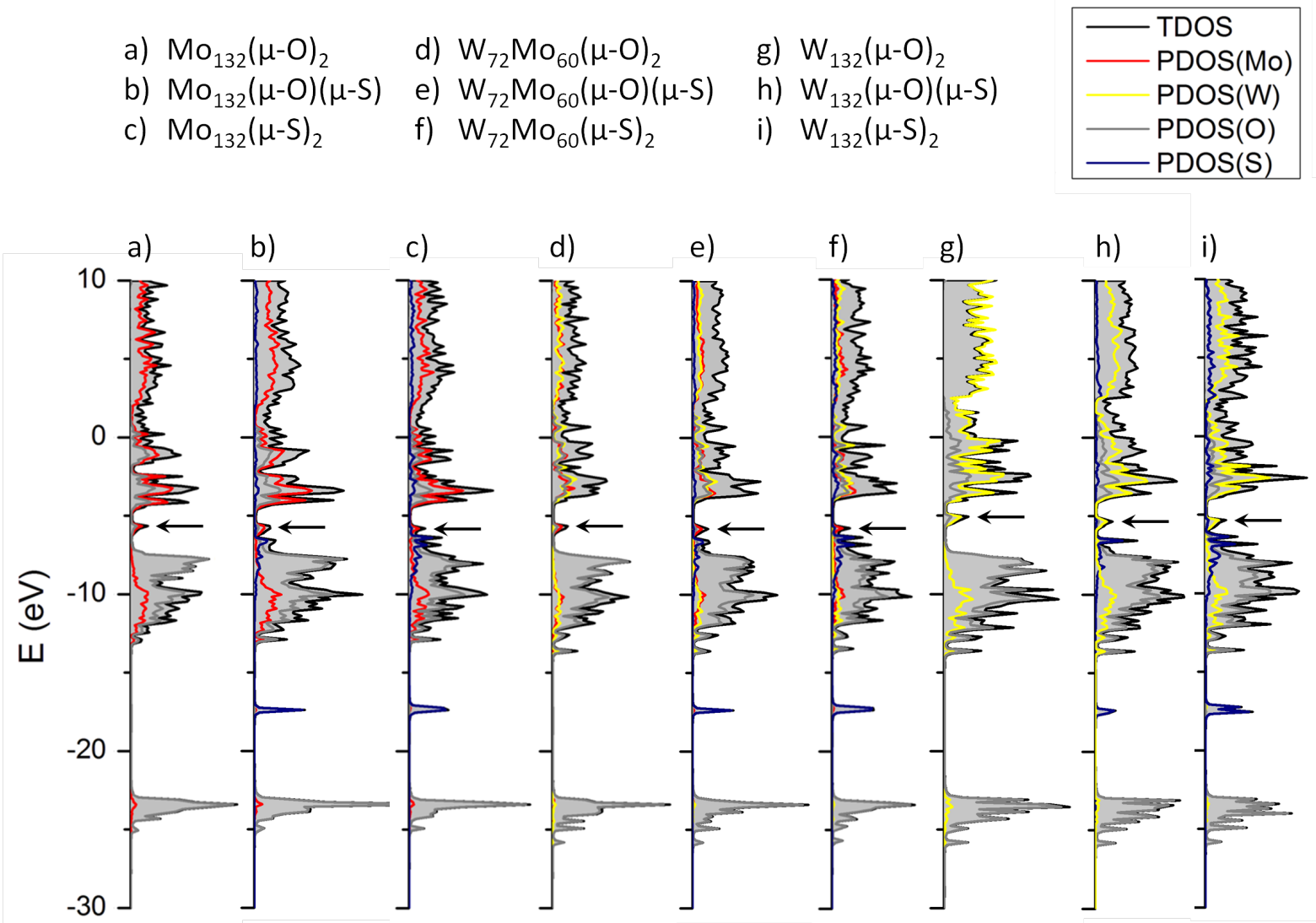

Figure 5: DOS for different Keplerates, including TDOS (black) and PDOS (red for Mo, yellow for W, grey for O and dark blue for S). Black arrows highlight the corresponding HOMO level for each system. 
Figure 5 compares the DOS for the set of Keplerates whose HOMO-LUMO gap was represented in Figure 4. Starting from the left, the first system $\mathrm{Mo}_{132}(\mu-\mathrm{O})_{2}$ has already been analyzed above (Figure 2). Figure 5 shows that the DOS of all the Keplerate family are quite similar, in terms of the HOMO and LUMO levels and the presence of the oxo-band. Nevertheless, there are some differences. The most distinctive feature is the appearance of new peaks associated with the sulfur electrons (Figure $5 \mathrm{~b}, \mathrm{~d}$, and e) in the case of thio-Keplerates. The $3 \mathrm{~s}$ sulfur orbitals are located between the $2 \mathrm{~s} 0$ orbitals band and the oxo-band. Also, $p$ orbitals related to these sulfur-bridges are found between the oxo-band and the HOMO band. It is worth noting that in the case of pure sulfur-bridges, the $3 \mathrm{~s}$ sulfur orbitals form two peaks (Figures $5 c, 5 f$ and $5 \mathrm{i}$ ), while only one peak appears in the case of mixed-bridges (Figures 5b, 5e, and $5 \mathrm{~h}$ ). This is due to the differences in energy of the bonding and antibonding orbitals of the sulfur atoms located at the bridges.

a)

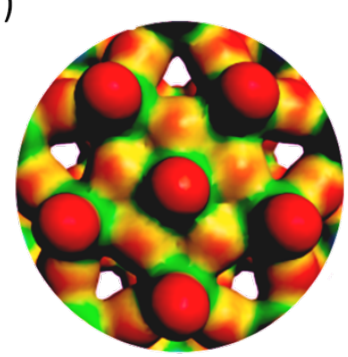

$\mathrm{Mo}_{132}(\mu-0)_{2}$

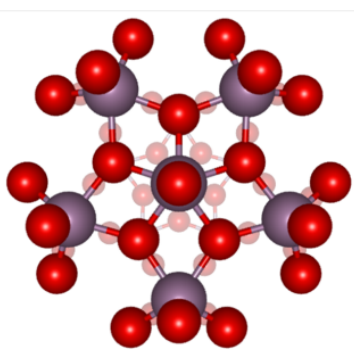

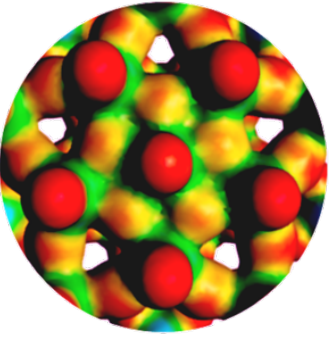

$\mathrm{W}_{72} \mathrm{Mo}_{60}(\mu-\mathrm{O})_{2}$

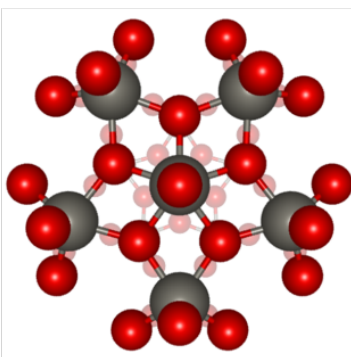

b)

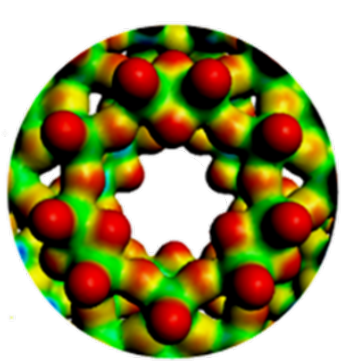

$\mathrm{Mo}_{132}(\mu-0)_{2}$

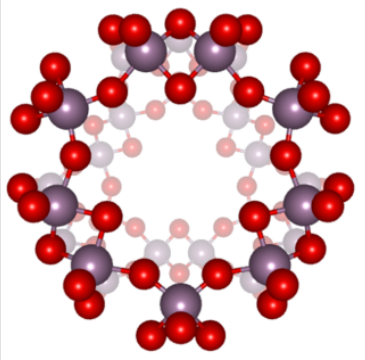

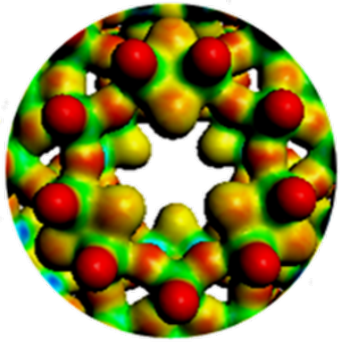

$\mathrm{Mo}_{132}(\mu-\mathrm{S})_{2}$

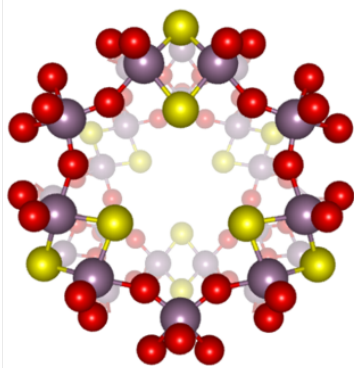

Figure 6: Top: Molecular Electrostatic Maps (MEP). Red color indicates negative MEP regions, while blue represents positive MEP areas. Bottom: Representations of the fragments represented in the MEP plots. In this case, purple and grey spheres stand for Mo and W atoms, respectively. Red and yellow spheres are reserved for oxygen and sulfur atoms. a) Comparison between the Mo (left) and W (right) based pentagonal units. b) Comparison between the pores of oxo- (left) and thio-Keplerates (right).

Besides DOS, Molecular Electrostatic Potential maps (MEP) are also a good tool for assessing the effects of chemical composition on the electronic properties of the systems. With this purpose, the electrostatic potential is projected onto the electronic density (see Supporting Information to see the complete graphical representation). All the five systems studied showed a very similar MEP pattern, which means that they should have a similar self-assembly behavior such as that found in blackberries. ${ }^{[49]}$ In spite of the very similar MEP patterns, there are some differences on the systems studied. When $W$ atoms form the pentagonal units, the oxygen atoms that link those metal centers are slightly less negatively charged than when Mo is present. This effect is due to the different properties of Mo-O and $\mathrm{W}-\mathrm{O}$ bond, resulting in less basic oxygens. The most remarkable difference between the MEP patterns is the change of the electrostatic potential when sulfur-bridges are present (Figure $6 \mathrm{~b}$ ). This change in the electrostatic potential in the vicinity of the pore together with the change in pore size, will lead to different pore-cation interactions in solution. The change in the 
electrostatic potential of the pore framework can also be observed when the electrostatic charges of the oxo- and sulfur-bridges are analyzed. For instance, in the case of the $\mathrm{Mo}_{132}$ capsule, when the bridging positions are occupied by $\mathrm{O}$ atoms they have a VDD charge of -0.38 whereas when they are occupied by $\mathrm{S}$ atoms, their charge decreases to -0.26 .

\section{Not Empty Capsules: Presence of Ligands and Coordination Water Molecules}

All the systems described in the previous section are experimentally characterized Keplerates that have been considered as empty capsules, which means that the POM has been treated as a polyanion with a charge of -12 since only the metal-oxo framework has been taken into account. To improve this model and check the effect of a more realistic description, different bidentate ligands were added as decoration of the inner surface of the $\mathrm{Mo}_{132}(\mu-O)_{2}$ capsule. Those ligands are experimentally known to be weakly attached to the linkers and they make these capsules even more negatively charged. The geometry optimizations performed for the system composed of $\operatorname{Mo}_{132}(\mu-O)_{2}$ and 30 ligands were carried out at the standard DFT level. To reduce the computational cost, these optimizations were carried out under the constraints of a $C_{i}$ molecular symmetry point group, with the exception of formate, carbonate, selenate, hypophosphite, and sulfate ligands. The fact that these ligands present a plane of symmetry, allows keeping the $D_{5 d}$ point group symmetry.

In the presence of ligands, the electronic levels of the $\mathrm{Mo}_{132}$ Keplerate are upshifted because of the increase in total charge (from -12 to -42 or -72 , depending on the ligand charge). The higher the ligand charge, the larger the shifting: for the -42 systems the DOS displacement is around $1 \mathrm{eV}$, while for -72 systems it is about $1.5 \mathrm{eV}$. The different shifts depending on the charge can be observed on the DOS as well as the new electronic levels due to the presence of the new ligands (The corresponding figures can be found in Supporting Information).

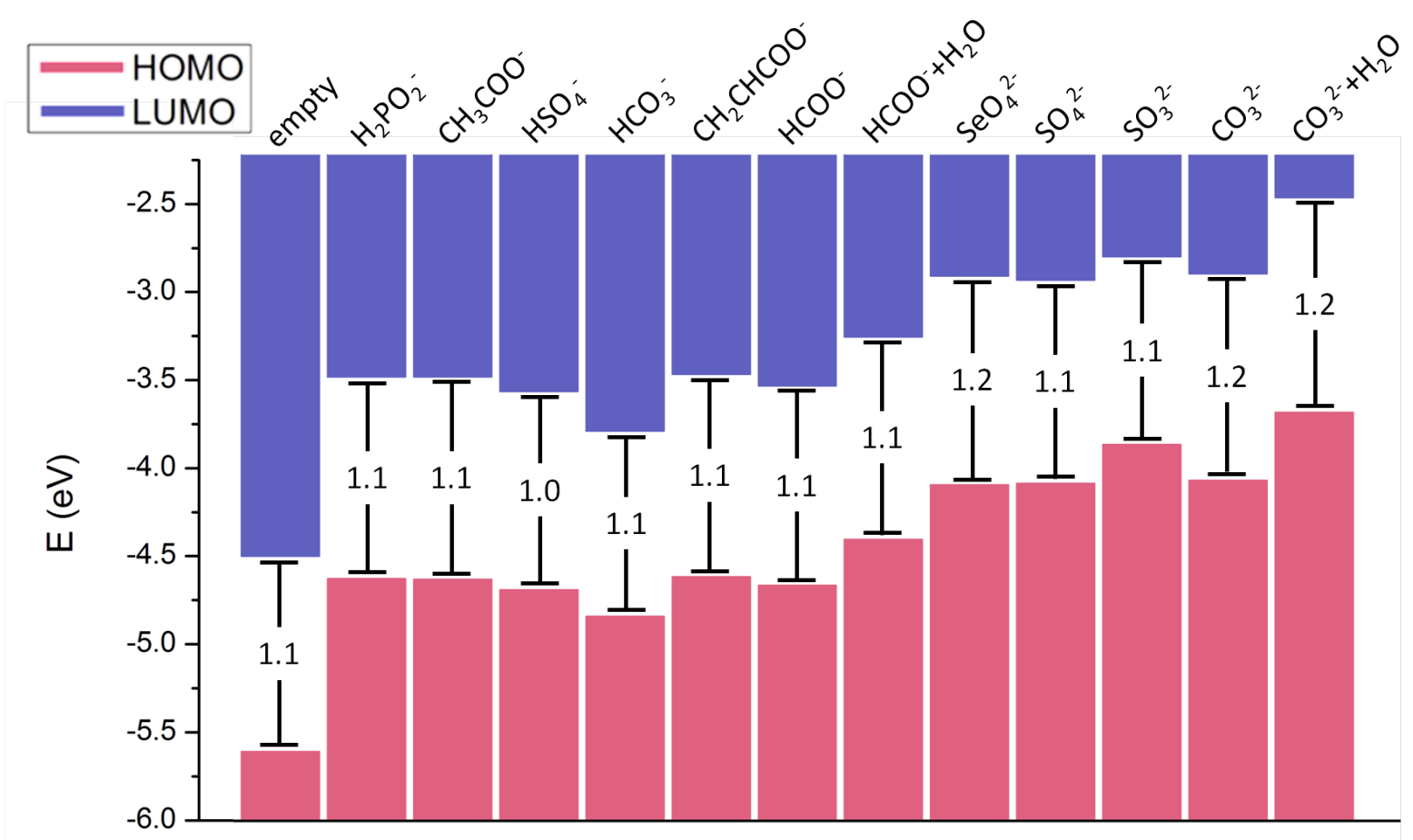


Figure 7: $\mathrm{HOMO}$ (pink), LUMO (violet) and the corresponding gap for the $\mathrm{Mo}_{132}(\mu-\mathrm{O})_{2}$ systems empty and coordinated with different bidentate ligands. The label " $+\mathrm{H}_{2} \mathrm{O}$ " indicates that, in addition of the mentioned ligands, 72 water molecules have been considered coordinated to the motifs.

Figure 7 shows that there is almost no change in the HOMO-LUMO gap when different inner ligands are considered. For instance, the empty $\mathrm{Mo}_{132}$ capsule has a gap of $1.1 \mathrm{eV}$. When acetate, bicarbonate, bisulfate, acrylate, hypophosphite, and formate groups are acting as internal ligands the system presents almost the same gap $(1.1 \mathrm{eV}$ for all the mentioned systems except for the bisulfate case, for which the computed gap is $1.0 \mathrm{eV}$ ). A very similar behavior is found when divalent ligands are considered. $\mathrm{SO}_{4}{ }^{2-}$ and $\mathrm{SO}_{3}{ }^{2-}$ systems have a gap about $1.1 \mathrm{eV}$. A slight increase of the HOMO-LUMO gap is found for the case of carbonate and selenate ligands (1.2 eV). The fact that the $\mathrm{Mo}_{132}$ capsule keeps almost constant its HOMO-LUMO gap upon changing the inner surface decoration means that the system's electronic stability is given by its inherent scaffold and is almost independent of the particular features of the specific ligands considered. In addition, in the case of formate and carbonate ligands the presence of coordination water molecules has been considered. The inclusion of such water molecules does not affect the HOMO-LUMO gap, but does shift the DOS (less than $1 \mathrm{eV}$ ).

Predicting New Members: $\operatorname{Mo}_{132}(\mu-O)(\mu-S)$, and $W_{132}, W_{132}(\mu-O)(\mu-S)$ and $W_{132}(\mu-S)_{2}$

The majority of the structures presented in the previous sections were already characterized by means of X-ray experiments reported in the literature. Nevertheless, there are more composition variants that can be envisaged and these were studied from a theoretical point of view. This section aims at evaluating the theoretical stability of these new systems in terms of their electronic structure, i.e. the HOMO-LUMO gap. Predicted new members of the Keplerate family are described in the following paragraphs, including $\mathrm{Mo}_{132}$ systems with different bridges compositions (sulfur- and mixed bridges) and full $\mathrm{W}_{132}$ systems (with oxo-, sulfur-, and mixed bridges).

Keplerates with $\mathrm{W}$ atoms hitherto introduced present $\mathrm{W}$ atoms only at the pentagonal motifs. So, the question that naturally arises is what would happen when W instead of Mo occupied the 132 metal centers. Also, as the $\mathrm{W}_{72} \mathrm{Mo}_{60}$ Keplerate has been synthesized with oxo-, thio- and mixed brides, it seems natural to analyze these possibilities both for the $\mathrm{Mo}_{132}$ and $\mathrm{W}_{132}$ molecules.

Figure 4 collects the HOMO and LUMO results for these new systems together with the systems presented in a previous section, and Figure 5 collects the DOS representation for these new systems (Figures $5 \mathrm{~b}, \mathrm{c}, \mathrm{g}, \mathrm{h}, \mathrm{i}$ ). The most remarkable result is that the HOMO level is not constant anymore for the $\mathrm{W}_{132}$ systems. This is because of the fact that the HOMO level is related to the metal-metal bond that involves the metal centers in the linkers (Figure 3f). Hence, changing from Mo linkers to $W$ linkers strongly affects bond properties, making the HOMO level higher in energy. Nevertheless, the LUMO level, related to the pentagonal metal centers (Figure $3 \mathrm{~g}$ ), is also higher in the case of $\mathrm{W}$ pentagons. Consequently, the HOMO-LUMO gap for the $\mathrm{W}_{132}$ systems is the same that for $\mathrm{Mo}_{132}$ systems. The comparatively high energy of the $\mathrm{W}_{132} \mathrm{HOMO}$ also brings into question the stability of these bonded electrons with respect to external oxidating agents or electrophiles. It is known that while dinuclear complexes dominate the oxo chemistry of MoV complexes, few analogous complexes are known to exist for $W^{V}$. These calculations provide a hint at explaining the difficulty in obtaining $W^{V}$ linkers. Two distinct chemical processes sourced from template libraries need to operate to form the Keplerate sphere: one is the formation of the star shaped moieties and the 
other is the co-existence of the pentavalent dimer at that narrow $\mathrm{pH}$ window to successfully follow through the condensation process. $A W^{V}$ oxo-dimer is less likely to form with such high energy electron pairs. $A W_{132}(\mu-S)_{2}$ Keplerate does however show to be a more promising candidate for a realizable synthetic procedure.

Furthermore, it is worth noting that the trend observed on the previous systems, i.e, HOMO-LUMO gap increase by introducing sulfur-bridges, is still present and the mixed-bridges Keplerates have an intermediate gap with respect to the pure oxo- and thio-cases.

\section{Conclusions}

Summing up, we have proven that all the members of the Keplerate family present very similar electronic structure profiles, regarding both the DOS and the values of the HOMO-LUMO gap. Moreover, we have shown that the presence of $\mathrm{W}$ in the pentagons and $\mathrm{S}$ in the bridging sites of the linkers increase the HOMO-LUMO gap, and, thus, the system's electronic stability. The inclusion of bidentate ligands and coordination water molecules in our model does not affect the HOMO-LUMO trend. Therefore, the capsule's stability is what determines the system's electronic stability, independently on the particularities of the internal decoration. We have also demonstrated that new Keplerates not synthesized yet, as the $\mathrm{W}_{132}$ with the different bridges possibilities and the $\mathrm{Mo}_{132}$ with mixed bridges, are stable from an electronic and theoretical point of view.

The results of this study suggest that the $W_{132}(\mu-S)_{2}$ Keplerate, i.e., $\left[W_{132} O_{312}(\mu-S)_{60}\right]^{12-}$ is the most promising candidate to be synthesized next. Since the ligands $L$ in the linkers does not affect the stability of the whole Keplerate in a significant extend, the choice of a suitable ligand for such synthesis should focus on increasing the stability of the dimeric species $\left[\mathrm{W}_{2} \mathrm{O}_{2}(\mu-S)_{2}\right]^{2+}$, since when it combines with the corresponding and already available $\left(\mathrm{W}_{6} \mathrm{O}_{21}\right)$ pentagonal building blocks, the full tungsten Keplerate should be readily formed.

\section{Acknowledgements}

The authors acknowledge the Spanish Ministerio de Economía y Competitividad (MINECO) through project CTQ2014-52824-R and the Severo Ochoa Excellence Accreditation 2014-2018 (SEV-20130319), and the AGAUR of Generalitat de Catalunya through project 2014-SGR-409 for financial support, and through the CERCA Programme. DM gratefully acknowledges URV-ICIQ fellowship. NAGB gratefully a Fundação para a Ciência e Tecnologia (grant SFRH/BPD/110419/2015) for funding.

\section{References}

[1] a)A. Müller, P. Gouzerh, Chem. Soc. Rev. 2012, 41, 7431-7463; b)H. N. Miras, J. Yan, D.-L. Long, L. Cronin, Chem. Soc. Rev. 2012, 41, 7403-7430. 
[2] a)A. Müller, P. Kögerler, A. Dress, Coord. Chem. Rev. 2001, 222, 193-218; b)A. Müller, E. Krickemeyer, H. Bögge, M. Schmidtmann, B. Botar, M. O. Talismanova, Angew. Chem. Int. Ed. 2003, 42, 2085-2090.

[3] A. Müller, S. Shah, H. Bögge, M. Schmidtmann, P. Kögerler, B. Hauptfleisch, S. Leiding, K. Wittler, Angew. Chem. Int. Ed. Engl. 2000, 39, 1614-1616.

[4] M.-Y. Gao, F. Wang, Z.-G. Gu, D.-X. Zhang, L. Zhang, J. Zhang, J. Am. Chem. Soc. 2016, 138, 2556-2559.

[5] a)A. Muller, K. Das, E. Krickemyer, C. KuhImann, Inorganic synthesis 2004, 34, 191-200; b)A. Proust, R. Thouvenot, P. Gouzerh, Chem. Commun. 2008, 1837-1852; c)A. Müller, V. P. Fedin, C. Kuhlmann, H. Bögge, M. Schmidtmann, Chem. Commun. 1999, 927-929.

[6] A. Müller, E. Krickemeyer, H. Bögge, M. Schmidtmann, S. Roy, A. Berkle, Angew. Chem., Int. Ed. 2002, 41, 3604-3609.

[7] S. Garai, M. Rubčić, H. Bögge, P. Gouzerh, A. Müller, Chem. Eur. J. 2015, 21, 4321-4325.

[8] S. Garai, E. T. K. Haupt, H. Bögge, A. Merca, A. Müller, Angew. Chem. Int. Ed. 2012, 51, 10528-10531.

[9] A. Müller, S. K. Das, S. Talismanov, S. Roy, E. Beckmann, H. Bögge, M. Schmidtmann, A. Merca, A. Berkle, L. Allouche, Y. Zhou, L. Zhang, Angew. Chem., Int. Ed. 2003, 42, 5039-5044.

[10] V. S. Korenev, P. A. Abramov, C. Vicent, A. A. Zhdanov, A. R. Tsygankova, M. N. Sokolov, V. P. Fedin, Dalton Trans. 2015, 44, 8839-8845.

[11] S. Garai, H. Bögge, A. Merca, O. A. Petina, A. Grego, P. Gouzerh, E. T. K. Haupt, I. A. Weinstock, A. Müller, Angew. Chem., Int. Ed. 2016, 55, 6634-6637.

[12] a)A. Ziv, A. Grego, S. Kopilevich, L. Zeiri, P. Miro, C. Bo, A. Müller, I. A. Weinstock, J. Am. Chem. Soc. 2009, 131, 6380-6382; b)C. Schäffer, A. M. Todea, H. Bögge, O. A. Petina, D. Rehder, E. T. K. Haupt, A. Müller, Chem. Eur. J. 2011, 17, 9634-9639; c)A. Grego, A. Müller, I. A. Weinstock, Angew. Chem. Int. Ed. 2013, 52, 8358-8362; d)A. Müller, L. Toma, H. Bogge, M. Henry, E. T. K. Haupt, A. Mix, F. L. Sousa, Chem. Commun. 2006, 3396-3398.

[13] T.-L. Lai, M. Awada, S. Floquet, C. Roch-Marchal, N. Watfa, J. Marrot, M. Haouas, F. Taulelle, E. Cadot, Chem. Eur. J. 2015, 21, 13311-13320.

[14] S. Kopilevich, H. Gottlieb, K. Keinan-Adamsky, A. Müller, I. A. Weinstock, Angew. Chem., Int. Ed. 2016, 55, 4476-4481.

[15] A. Müller, E. Krickemeyer, H. Bögge, M. Schmidtmann, F. Peters, Angew. Chem. Int. Ed. 1998, 37, 3360-3363.

[16] A. Müller, S. Sarkar, S. Shah, H. Bögge, M. Schmidtmann, P. Kögerler, B. Hauptfleisch, A. Trautwein, V. Schünemann, Angew. Chem. Int. Ed. Engl. 1999, 38, 3238-3241.

[17] A. Müller, A. M. Todea, J. van Slageren, M. Dressel, H. Bögge, M. Schmidtmann, M. Luban, L. Engelhardt, M. Rusu, Angew. Chem. Int. Ed. 2005, 44, 3857-3861.

[18] A. M. Todea, A. Merca, H. Bögge, J. van Slageren, M. Dressel, L. Engelhardt, M. Luban, T. Glaser, M. Henry, A. Müller, Angew. Chem. Int. Ed. 2007, 46, 6106-6110.

[19] C. Schäffer, A. Merca, H. Bögge, A. M. Todea, M. L. Kistler, T. Liu, R. Thouvenot, P. Gouzerh, A. Müller, Angew. Chem., Int. Ed. 2009, 48, 149-153.

[20] A. Müller, M. Koop, H. Bögge, M. Schmidtmann, F. Peters, P. Kögerler, Chem. Commun. 1999, 1885-1886.

[21] F. Bannani, S. Floquet, N. Leclerc-Laronze, M. Haouas, F. Taulelle, J. Marrot, P. Kögerler, E. Cadot, J. Am. Chem. Soc. 2012, 134, 19342-19345.

[22] C. Schäffer, A. M. Todea, H. Bögge, E. Cadot, P. Gouzerh, S. Kopilevich, I. A. Weinstock, A. Müller, Angew. Chem. Int. Ed. 2011, 50, 12326-12329.

[23] C. Schäffer, A. M. Todea, H. Bögge, S. Floquet, E. Cadot, V. S. Korenev, V. P. Fedin, P. Gouzerh, A. Müller, Dalton Trans. 2012, 42, 330.

[24] N. V. Izarova, O. A. Kholdeeva, M. N. Sokolov, Russ. Chem. Bull. 2009, 58, 134-137.

[25] D. Fan, J. Hao, J. Phys. Chem. B 2009, 113, 7513-7516. 
[26] S. Kopilevich, A. Gil, M. Garcia-Ratés, J. Bonet-Ávalos, C. Bo, A. Müller, I. A. Weinstock, J. Am. Chem. Soc. 2012, 134, 13082-13088.

[27] C. Besson, S. Schmitz, K. M. Capella, S. Kopilevich, I. A. Weinstock, P. Kögerler, Dalton Trans. 2012, 41, 9852.

[28] N. A. G. Bandeira, S. Garai, A. Muller, C. Bo, Chem. Commun. 2015, 51, 15596-15599.

[29] a)A. Rezaeifard, R. Haddad, M. Jafarpour, M. Hakimi, J. Am. Chem. Soc. 2013, 135, 1003610039; b)A. Nakhaei, A. Davoodnia, Chinese Journal of Catalysis 2014, 35, 1761-1767; c)A. Rezaeifard, R. Haddad, M. Jafarpour, M. Hakimi, ACS Sustainable Chem. Eng. 2014, 2, 942950; d)C. Yang, W. Zhao, Z. Cheng, B. Luo, D. Bi, RSC Adv. 2015, 5, 36809-36812; e)A. Nakhaei, A. Davoodnia, A. Morsali, Res. Chem. Int. 2015, 41, 7815-7826; f)A. Rezaeifard, M. Jafarpour, R. Haddad, H. Tavallaei, M. Hakimi, J. Cluster Sci. 2015, 26, 1439-1450; g)E. Nikbakht, B. Yadollahi, M. R. Farsani, Inorg. Chem. Comm. 2015, 55, 135-138; h)F. Jalilian, B. Yadollahi, M. R. Farsani, S. Tangestaninejad, H. A. Rudbari, R. Habibi, Catal. Commun. 2015, 66, 107-110; i)H. Haddadi, E. Korani, S. Hafshejani, M. Farsani, J. Cluster Sci. 2015, 26, $1913-$ 1922.

[30] H. Li, Y. Yang, Y. Wang, C. Wang, W. Li, L. Wu, Soft Matter 2011.

[31] S. Floquet, E. Terazzi, A. Hijazi, L. Guénée, C. Piguet, E. Cadot, New J. Chem. 2012, 36, 865.

[32] N. Watfa, S. Floquet, E. Terazzi, W. Salomon, L. Guénée, K. Buchwalder, A. Hijazi, D. Naoufal, C. Piguet, E. Cadot, Inorganics 2015, 3, 246-266.

[33] J. Gooch, A. A. Jalan, S. Jones, C. R. Hine, R. Alam, S. Garai, M. M. Maye, A. Müller, J. Zubieta, J. Colloid Interface Sci. 2014, 432, 144-150.

[34] Q. Chen, L. Yang, C. Zheng, W. Zheng, J. Zhang, Y. Zhou, J. Liu, Nanoscale 2014, 6, 6886-6897. [35] C. Bo, P. Miro, Dalton Trans. 2012, 41, 9984-9988.

[36] K. Kuepper, C. Derks, C. Taubitz, M. Prinz, L. Joly, J.-P. Kappler, A. Postnikov, W. Yang, T. V. Kuznetsova, U. Wiedwald, P. Ziemann, M. Neumann, Dalton Trans. 2013, 42, 7924.

[37] a)T. Mitra, P. Miro, A.-R. Tomsa, A. Merca, H. Bögge, J. B. Avalos, J. M. Poblet, C. Bo, A. Müller, Chem. Eur. J. 2009, 15, 1844-1852; b)M. Garcia-Ratés, P. Miro, J. M. Poblet, C. Bo, J. B. Avalos, J. Phys. Chem. B 2011, 115, 5980-5992; c)M. Garcia-Ratés, P. Miro, A. Müller, C. Bo, J. B. Avalos, J. Phys. Chem. C 2014, 118, 5545-5555.

[38] N. Watfa, D. Melgar, M. Haouas, F. Taulelle, A. Hijazi, D. Naoufal, J. B. Avalos, S. Floquet, C. Bo, E. Cadot, J. Am. Chem. Soc. 2015, 137, 5845-5851.

[39] a)K. Goutham, E. Mani, J. Mol. Eng. Mater. 2014, 02, 1440005; b)E. Mani, E. Sanz, S. Roy, M. Dijkstra, J. Groenewold, W. K. Kegel, J. Chem. Phys. 2012, 136, 144706.

[40] a)E. van Lenthe, E. J. Baerends, J. G. Snijders, J. Chem. Phys. 1994, 101, 9783-9792; b)G. te Velde, F. M. Bickelhaupt, E. J. Baerends, C. Fonseca Guerra, S. J. A. van Gisbergen, J. G. Snijders, T. Ziegler, J. Comput. Chem. 2001, 22, 931-967; c)C. F. Guerra, J. Snijders, G. Te Velde, E. Baerends, Theor. Chem. Acc. 1998, 99, 391-403.

[41] a)A. D. Becke, J. Chem. Phys. 1993, 98, 1372-1377; b)J. P. Perdew, Physical Review B 1986, 33, 8822-8824.

[42] a)E. v. Lenthe, E. J. Baerends, J. G. Snijders, J. Chem. Phys. 1993, 99, 4597-4610; b)E. van Lenthe, A. Ehlers, E.-J. Baerends, J. Chem. Phys. 1999, 110, 8943-8953.

[43] a)A. Klamt, G. Schuurmann, J. Chem. Soc., Perkin Trans. 1 1993, 799-805; b)C. C. Pye, T. Ziegler, Theor. Chem. Acc. 1999, 101, 396-408.

[44] N. L. Allinger, X. Zhou, J. Bergsma, J. Mol. Struct. 1994, 312, 69-83.

[45] S. H. Vosko, L. Wilk, M. Nusair, Can. J. Phys. 1980, 58, 1200-1211.

[46] http://dx.doi.org/10.19061/iochem-bd-1-24

[47] M. Álvarez-Moreno, C. de Graaf, N. López, F. Maseras, J. M. Poblet, B. C, J. Chem. Inf. Model. 2015, 55, 95-103.

[48] C. Schaffer, A. M. Todea, H. Bogge, S. Floquet, E. Cadot, V. S. Korenev, V. P. Fedin, P. Gouzerh, A. Muller, Dalton Trans. 2013, 42, 330-333. 
[49] a)F. Haso, X. Fang, P. Yin, D. Li, J. L. Ross, T. Liu, Chem. Commun. 2013, 49, 609-611; bP. Yin, D. Li, T. Liu, Chem. Soc. Rev. 2012, 41, 7368-7383; c)Y. Wang, I. A. Weinstock, Dalton Trans. 2010, 39, 6143-6152.

For the Table of contents

Which one is next? The electronic structure of metal oxide molecular nanocapsules known as Keplerates was described at the DFT level. This study considered several combinations of the metal atoms (Mo / W), of the bridging atoms (O / S) and also of internal ligands, discusses stability trends, and predicts the stability of not synthesized yet species: $\left[\mathrm{W}_{132} \mathrm{O}_{312}(\mu-\mathrm{S})_{60}\right]^{12-}$ is the most promising candidate to be synthesized next.

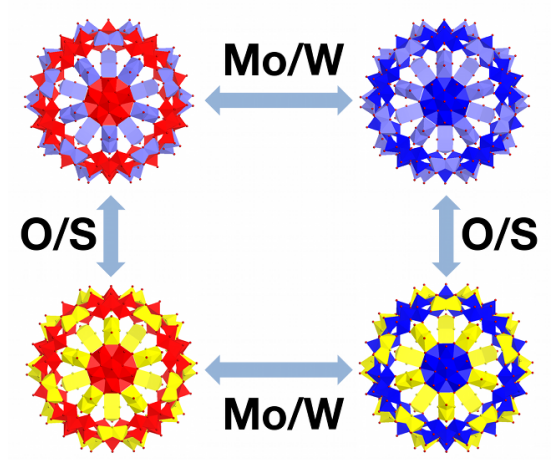

